\title{
22. ELEMENTAL COMPOSITION AND PETROLEUM-GENERATING POTENTIAL OF THE METHYLENE CHLORIDE EXTRACTS FROM LEG 66 SAMPLES ${ }^{1}$
}

\author{
R. L. Chambers and J. G. Erdman, Phillips Petroleum Company, Bartlesville, Oklahoma
}

\section{INTRODUCTION}

Organic geochemical studies on samples from Holes 487, 488, and 490 in the southern Mexico Middle America Trench provided an opportunity to characterize the organic fraction of the sedimentary section in an active trench environment and to project the petroleum-producing potential of the extracted lipid fractions.

The samples were geologically young and of shallow burial history. Samples from Hole 487, located on the oceanic plate, range in age from late Miocene to middlelate Pleistocene. Samples from Hole 488, representing undifferentiated Quaternary sediment, were collected on the landward side of the lower trench slope. Miocene(?) to Quaternary sediments from Hole 490 were obtained from the upper slope immediately seaward of the inferred location of the continental crust. The site locations and bathymetry are shown in Figure 1.

\section{GEOLOGY}

The continental margin in the Leg 66 study area is described as a narrow crustal transition zone with an unusually shallow but steep-walled trench slope (Shipley et al., 1980). The shallowness of the trench is probably related to the youth of the subducting crust (Larson and Chase, 1970).

Trench floor and lower slope sediments consist of turbidite deposits, whereas slope apron and ocean crust sediments consist of hemipelagic and pelagic deposits, respectively (Seely et al., 1974; Shipley et al., 1980). It has been suggested that accretion of oceanic sediments, trench turbidite fill, and hemipelagic apron material into the toe or inner wall is by folding and imbricate thrusting (Seely et al., 1974), a thesis supported in part by later studies (Shipley et al., 1980). Volume calculations suggest consumption of the sedimentary rocks (Shipley et al., 1980).

\section{SAMPLING AND ANALYTICAL PROCEDURES}

The frozen samples, which were cut vertically, constituted quarters of the core sections. Each was freed of contaminating mud as thoroughly as possible, dehydrated, and then ground to a homogeneous powder.

Total organic and carbonate carbon were determined by combustion, total nitrogen by Kjeldahl, and total sulfur (which includes elemental sulfur, organic sulfur, pyrite sulfur, and sulfate) by LECO combustion.

Fifty-gram aliquots from four samples were extracted with methylene chloride that had been purified by distillation in glass. The

\footnotetext{
1 Initial Reports of the Deep Sea Drilling Project, Volume 66.
}

extracts were centrifuged to remove suspended matter, the solvent evaporated, and the amount of extract determined gravimetrically.

All values were determined by direct analysis. Carbon, hydrogen, nitrogen, and sulfur were determined by combustion and quantified by gas chromatography (Iorns and Scott, 1980). Oxygen was determined by pyrolysis in helium and conversion of the oxygen to carbon monoxide, which was quantitated by gas chromatography (Scott, 1980).

\section{RESULTS AND DISCUSSION}

Sampling depth, estimated age, organic and carbonate carbon, total nitrogen, and total sulfur are shown in Table 1.

Organic carbon concentration decreases greatly with depth in Hole 487. This trend suggests a progressive increase in the influx of organic matter, a progressive decrease in biogenic oxidation from the late Miocene to the middle-late Pleistocene, or both. There is also a parallel downward trend in the total nitrogen values. No trends are evident either in carbonate carbon or total sulfur. In the middle Pleistocene there is a nearly tenfold increase in carbonate carbon. The concentration, expressed as calcium carbonate, is $13.6 \%$.

Organic carbon concentration also decreases downcore in Hole 488, but the trend is not as strong as in Hole 487. No trend is evident in the concentration of total nitrogen. Carbonate carbon concentrations are low and relatively constant throughout the portion of the core included in this study.

There are no clear trends in the content of organic carbon, total nitrogen, or total sulfur in Hole 490. An interval of higher carbonate carbon content is observed at 366.6 meters (Pliocene?). The concentration, expressed as calcium carbonate, is $11.1 \%$.

Table 2 shows the amount of lipid, extracted by methylene chloride, in terms of the dry weight of the sediment and the elemental composition of the extract normalized to 10 carbon atoms. Crystals of elemental sulfur were observed in Samples 487-2-3, 125 to $150 \mathrm{~cm}$ and $488-5-1,120$ to $150 \mathrm{~cm}$, which suggests that much of the sulfur in the extracts is chemically uncombined, a state consistent with the short and low temperature history of these samples. Assuming that the sulfur is present as the uncombined element, organic lipids comprise only 60.5 and $13.1 \%$, respectively, of the methylene chloride extract of these two samples. These data also indicate that large errors are possible when the weight of the extract is assumed to represent the amount of lipid organic matter.

The projected potential of the extracted lipid fraction to generate petroleums and associated products by natu- 


\section{R. L. CHAMBERS, J. G. ERDMAN}

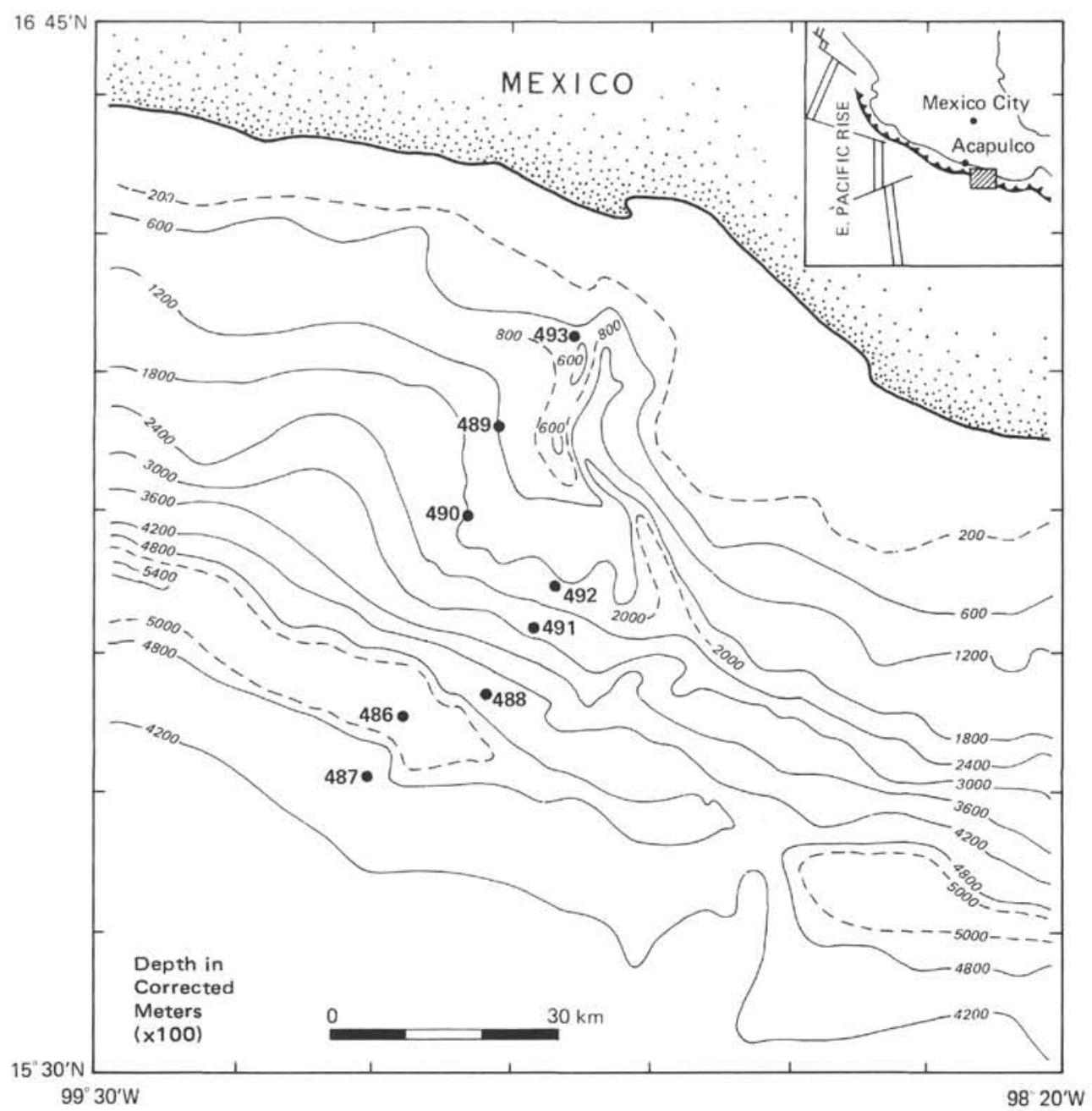

Figure 1. Location of sites from which samples were obtained for geochemical study.

Table 1. Depth, geologic age, and concentrations of carbon, nitrogen, and sulfur in the sediment samples, Holes 487, 488, and 490 .

\begin{tabular}{|c|c|c|c|c|c|c|}
\hline \multirow{2}{*}{$\begin{array}{c}\text { Sample } \\
\text { (interval in } \mathrm{cm} \text { ) }\end{array}$} & \multirow{2}{*}{$\begin{array}{l}\text { Sub-bottom } \\
\text { Depth (m) }\end{array}$} & \multirow[b]{2}{*}{ Geologic Age } & \multicolumn{2}{|c|}{ Carbon } & \multirow{2}{*}{$\begin{array}{l}\text { Nitrogen } \\
\text { (total) }\end{array}$} & \multirow{2}{*}{$\begin{array}{l}\text { Sulfur } \\
\text { (total) }\end{array}$} \\
\hline & & & Organic & Carbonate & & \\
\hline \multicolumn{7}{|l|}{ Hole 487} \\
\hline $2-3,125-150$ & 4.138 & middle-late Pleistocene & 2.04 & 0.08 & 0.11 & 0.43 \\
\hline $6-3,120-150$ & 42.14 & middle Pleistocene & 1.19 & 1.71 & 0.22 & \\
\hline $9-6,120-150$ & 75.14 & early-middle Pleistocene & 0.93 & 0.12 & 0.08 & 0.61 \\
\hline $12-4,120-150$ & 100.6 & early-middle Pleistocene & 0.59 & 0.20 & 0.02 & \\
\hline $15-5,120-150$ & 130.6 & late Miocene & 0.16 & $<0.02$ & 0.01 & \\
\hline $18-5,110-140$ & 159.1 & late Miocene & 0.09 & 0.03 & $<0.01$ & \\
\hline \multicolumn{7}{|l|}{ Hole 488} \\
\hline $5-1,120-150$ & 29.64 & late Quaternary & 2.38 & 0.31 & 0.17 & 0.55 \\
\hline $10-4,120-150$ & 81.64 & middle-late Quaternary & 2.24 & 0.32 & 0.15 & \\
\hline $19-4,120-150$ & 166.1 & middle-late Quaternary & 1.92 & 0.22 & 0.17 & \\
\hline $22-1,130-150$ & 191.1 & Quaternary & 1.67 & 0.30 & 0.11 & \\
\hline $29-4,120-130$ & 262.1 & Quaternary & 1.27 & 0.16 & 0.14 & \\
\hline $42-2,110-140$ & 382.6 & Quaternary & 1.30 & 0.24 & 0.10 & \\
\hline \multicolumn{7}{|l|}{ Hole 490} \\
\hline $2-4,110-130$ & 13.62 & Quaternary & 2.11 & 0.07 & 0.14 & 1.14 \\
\hline $5-5,110-140$ & 43.63 & Quaternary & 2.40 & 0.70 & 0.20 & 1.47 \\
\hline $8-2,110-140$ & 67.63 & Quaternary & 2.62 & & & \\
\hline $18-5,110-140$ & 167.1 & late Pliocene & 2.13 & 0.27 & 0.22 & \\
\hline $21-5,110-140$ & 195.6 & late Pliocene & 2.48 & 0.44 & 0.21 & 0.72 \\
\hline $29-3,110-140$ & 268.6 & Pliocene & 1.71 & 0.11 & 0.15 & \\
\hline $34-2,110-135$ & 305.1 & Pliocene(?) & 1.47 & 0.16 & 0.11 & \\
\hline $40-5,110-135$ & 366.6 & Pliocene(?) & 2.90 & 1.40 & 0.25 & \\
\hline $54-3,120-150$ & 487.1 & Pliocene & 1.61 & $<0.01$ & 0.12 & 1.06 \\
\hline $59-3,110-140$ & 534.6 & Miocene & 1.31 & 0.08 & 0.10 & 0.70 \\
\hline
\end{tabular}

Note: Concentrations are in percent of the dry weight of the sediment. 
Table 2. Amount and composition of the extract fraction.

\begin{tabular}{ccccccc}
\hline $\begin{array}{c}\text { Sample } \\
\text { (interval in cm) }\end{array}$ & $\begin{array}{c}\text { Amount } \\
\text { (\% of dry wt. } \\
\text { of sediment) }\end{array}$ & \multicolumn{4}{c}{$\begin{array}{c}\text { Number of Atoms/ } \\
10 \text { Carbon Atoms }\end{array}$} \\
\hline $\begin{array}{c}487-2-3, \\
120-150\end{array}$ & 0.0442 & 17.2 & 0.787 & 0.089 & 3.08 \\
$\begin{array}{c}487-9-6, \\
120-150\end{array}$ & 0.0323 & 18.3 & 0.506 & 0.027 & 0.14 \\
$\begin{array}{c}488-5-1, \\
120-150\end{array}$ & 0.264 & 20.1 & 1.86 & 0.221 & 32.3 \\
$490-59-3$, & 0.0302 & 17.6 & 0.638 & 0.049 & 0.20 \\
$110-140$ & & & & & \\
\hline
\end{tabular}

ral thermolytic degradation is shown in Tables 4 and 5 and in Figures 2 and 3. These deductions are based on a stoichiometric calculation procedure described earlier (Erdman, 1972, 1975). In this projection the objective is to maximize yields of the three types of petroleum products - that is, to assume future events most favorable to generation of petroleum. Accordingly, additional oxidant, such as the biological reduction of sulfate and abiogenic oxidation of hydrogen sulfide, was not included in these calculations. Emphasis on the lipid fraction is consistent with the widely accepted view that the lipids are the principal precursors of petroleum.

The four lipid fractions, whose elemental compositions are given in Table 2, were treated as the precursors. In each case three petroleums and four kerogens were designated as potential products. The three petroleums are natural gas (methane), condensate, and a typical heavy crude oil ( $\sim 20$ API Gravity). We used kerogen compositions typical of marine origin. Increasing degrees of thermolysis, indicated by decreasing hydrogen-to-carbon ratios, reflect increasing geological time and exposure to rising temperatures as a consequence of deeper burial. For example, a hydrogen-to-carbon ratio of 1.3 is typical of late Tertiary and of burial of 1000 meters at a normal geothermal gradient-that is, $3^{\circ} \mathrm{C} /$ $100 \mathrm{~m}$. A hydrogen-to-carbon ratio of 0.4 would be typical of late Paleozoic or early Mesozoic and deep burial of 5000 to 6500 meters, again assuming a normal geothermal gradient. The elemental compositions of the petroleums and kerogens are provided in Table 3. Although the sulfur already present in the extracts is not included in the compositions, we will consider the possible effect of elemental sulfur interaction later.

Thermolytic degradation results of the lipid fraction of Sample 487-2-3, 125-150 cm are shown in Table 4, Part A, and in Figure 2, A-C. For each of the three petroleum types, the yields increase with a decrease in the hydrogen-to-carbon ratio of the associated kerogen. For all cases, the yield of methane is less than the yield of condensate. This difference is the consequence of a higher hydrogen requirement for methane-versus-condensate formation.

The limitations imposed by mass balance rule out the formation of heavy crude oil for samples in this study. To form heavy oil, the associated kerogens would need a hydrogen-to-carbon ratio greater than 1.3. Kerogens with such high ratios have not been found in nature and are not likely to exist.
Table 3. Composition of reference compounds used in the stoichiometric calculations.

\begin{tabular}{|c|c|c|c|}
\hline \multicolumn{4}{|c|}{ Part A. Petroleums } \\
\hline \multirow[b]{2}{*}{ Type } & \multicolumn{3}{|c|}{$\begin{array}{l}\text { Number of Atoms/ } \\
10 \text { Carbon Atoms }\end{array}$} \\
\hline & $\mathrm{H}$ & $\mathrm{O}$ & $\mathrm{N}$ \\
\hline Natural Gas (methane) & 40 & - & - \\
\hline Condensate & 20 & - & - \\
\hline Heavy Crude Oil & 13.1 & 0.14 & 0.01 \\
\hline \multicolumn{4}{|c|}{ Part B. Kerogens } \\
\hline \multicolumn{4}{|c|}{$\begin{array}{l}\text { Number of Atoms/ } \\
10 \text { Carbon Atoms }\end{array}$} \\
\hline Aromatization & $\mathrm{H}$ & $\mathrm{O}$ & $\mathrm{N}$ \\
\hline \multirow[b]{4}{*}{1} & 13 & 0.30 & 0.01 \\
\hline & 10 & 0.20 & 0.01 \\
\hline & 7 & 0.15 & 0.01 \\
\hline & 4 & 0.10 & 0.01 \\
\hline
\end{tabular}

As shown in Table 4, Part A, and in Figure 2C, a mixture of natural gas (methane) and heavy crude oil can be formed. In fact, natural gas and crude oils often coexist in reservoirs. Of the three petroleum types treated in these calculations, the highest yield from this lipid would be condensate, amounting to $71.2 \%$.

Similar results for natural gas (methane) and condensate from the lipid fractions of Samples 487-9-6, 120 $150 \mathrm{~cm}, 488-5-1,120-150 \mathrm{~cm}$, and 490-59-3, 110-140 cm are provided in Table 4, Parts B and C. Yields are similar to those for Sample 487-2-3, 120-150 cm. Sample $487-9-6,120-150 \mathrm{~cm}$ has the highest capacity for conversion to petroleum, with an $82.3 \%$ potential conversion to condensate.

Table 2 shows that the extracts contain appreciable amounts of sulfur, which is believed to be primarily elemental. Reaction of elemental sulfur with organic source material will affect the yields of petroleum and kerogen.

Elemental sulfur reacts with organic matter according to one of two scenarios. The first involves abstraction of hydrogen from the organic matter to form hydrogen sulfide. The second is chemical combination of the sulfur with the kerogen and, to a lesser extent, with the petroleum. At normal ocean bottom temperature, elemental sulfur does not react to any significant extent with organic matter. As temperature increases with burial, however, the sulfur begins to react. Table 5, Parts A and B, and Figure 3, A and B, show the yields of petroleum and kerogen according to both scenarios.

The thermolytic degradation of a sulfur-containing extract, according to the first scenario, is shown in Figure $3 \mathrm{~A}$ and in Table 5, Part A. The major zone of reaction appears to correspond with kerogen hydrogen-tocarbon ratios between 1.0 and 0.7 . As sulfur reacts to form hydrogen sulfide, natural gas (methane) production decreases, with a concomitant increase in kerogen (solid lines). After conversion of the sulfur to hydrogen 
Table 4. Projection of the natural thermolytic ${ }^{\mathrm{a}}$ degradation of the lipid fraction.

\begin{tabular}{|c|c|c|c|c|c|}
\hline $\begin{array}{l}\text { Petrolcum } \\
\text { (type) }\end{array}$ & $\begin{array}{c}\text { H-to-C Ratio } \\
\text { (kerogen) }\end{array}$ & Kerogen & $\begin{array}{l}\text { Carbon } \\
\text { Dioxide }\end{array}$ & Water & Ammonia \\
\hline \multicolumn{6}{|c|}{ Part A. Sample $487-2-3,120-150 \mathrm{~cm}$} \\
\hline \multicolumn{6}{|c|}{ (natural gas-methane) } \\
\hline 14.2 & 1.3 & 77.8 & 4.0 & 3.1 & 0.91 \\
\hline 22.9 & 1.0 & 67.7 & 4.6 & 3.7 & 0.92 \\
\hline 30.2 & 0.7 & 59.8 & 5.0 & 4.0 & 0.93 \\
\hline $\begin{array}{c}36.2 \\
\text { (condensate) }\end{array}$ & 0.4 & 53.3 & 5.3 & 4.3 & 0.93 \\
\hline 47.2 & 1.3 & 43.2 & 5.0 & 3.6 & 0.95 \\
\hline 59.6 & 1.0 & 29.9 & 5.4 & 4.1 & 0.96 \\
\hline 66.6 & 0.7 & 22.5 & 5.5 & 4.4 & 0.97 \\
\hline 71.2 & 0.4 & 17.8 & 5.6 & 4.5 & 0.98 \\
\hline \multicolumn{6}{|c|}{$\begin{array}{l}\left(50-50 \mathrm{wt} . \%_{0}\right) \\
\text { natural gas and } \\
\text { heavy crude oil }\end{array}$} \\
\hline 28.4 & 1.3 & 63.3 & 4.4 & 3.2 & 0.90 \\
\hline 41.1 & 1.0 & 49.6 & 4.7 & 3.8 & 0.92 \\
\hline 49.7 & 0.7 & 40.5 & 5.0 & 4.0 & 0.93 \\
\hline 56.0 & 0.4 & 33.8 & 5.1 & 4.2 & 0.93 \\
\hline
\end{tabular}

Part B. Sample 487-9-6, 120-150 cm

$\begin{array}{cccccc}\text { (natural gas-methane) } & & & & & \\ 20.6 & 1.3 & 75.5 & 2.0 & 1.6 & 0.22 \\ 29.1 & 1.0 & 65.7 & 2.7 & 2.2 & 0.23 \\ 36.1 & 0.7 & 58.0 & 3.1 & 2.5 & 0.24 \\ 42.0 & 0.4 & 51.7 & 3.4 & 2.7 & 0.24 \\ \text { (condensate) } & & & & & \\ 68.2 & 1.3 & 27.7 & 3.4 & 2.4 & 0.28 \\ 75.5 & 1.0 & 17.8 & 3.6 & 2.8 & 0.29 \\ 79.8 & 0.7 & 13.3 & 3.7 & 2.9 & 0.30 \\ 82.3 & 0.4 & 10.7 & 3.7 & 3.0 & 0.30\end{array}$

Part C. Sample 488-5-1, 120-150 cm

$\begin{array}{cccccc}\text { (natural gas-methane) } & & & & & \\ 18.6 & 1.3 & 60.4 & 10.6 & 8.3 & 2.10 \\ 25.4 & 1.0 & 52.6 & 11.1 & 8.8 & 2.11 \\ 31.0 & 0.7 & 46.5 & 11.3 & 9.1 & 2.11 \\ 35.7 & 0.4 & 41.4 & 11.5 & 9.3 & 2.12 \\ \text { (condensate) } & & & & & \\ 62.4 & 1.3 & 14.5 & 12.2 & 8.8 & 2.16 \\ 66.1 & 1.0 & 10.6 & 12.0 & 9.2 & 2.16 \\ 68.4 & 0.7 & 8.1 & 11.9 & 9.4 & 2.16 \\ 69.9 & 0.4 & 6.5 & 11.8 & 9.5 & 2.17\end{array}$

Part D. Sample 490-59-3, 110-140 cm

(natural gas-methane)

$\begin{array}{cccccc}17.0 & 1.3 & 77.3 & 2.9 & 2.3 & 0.47 \\ 25.7 & 1.0 & 67.3 & 3.7 & 2.9 & 0.48 \\ 32.9 & 0.7 & 59.4 & 4.0 & 3.2 & 0.48 \\ 38.9 & 0.4 & 52.9 & 4.3 & 3.5 & 0.49 \\ \text { (condensate) } & & & & & \\ 56.3 & 1.3 & 36.2 & 4.1 & 3.0 & 0.52 \\ 66.6 & 1.0 & 25.0 & 4.4 & 3.4 & 0.53 \\ 72.5 & 0.7 & 18.8 & 4.6 & 3.6 & 0.54 \\ 76.2 & 0.4 & 14.9 & 4.6 & 3.7 & 0.54\end{array}$

${ }^{\text {a }}$ Effect of geologic time and geothermal gradient. Extent of degradation is indicated by the $\mathrm{H}$-to-C ratio.

sulfide is complete, the yield of natural gas (methane) slowly increases. The dashed lines in the natural gas and kerogen fields show product yields, assuming that sulfur reacts completely once the hydrogen-to-carbon ratio decreases to 1 .

A model of the second scenario is shown in Figure 3B and in Table 5, Part B. In this case, half the sulfur reacts to form hydrogen sulfide and half combines chemically with the kerogen. The trend in the natural gas yields are similar but less sharp than in the first scenario; kerogen increases significantly through the reaction zone, however. As in the previous case, once the sulfur reaction is complete, natural gas production increases, with decreasing kerogen yields. The dashed lines indicate product yields, assuming that sulfur reacts immediately and completely.
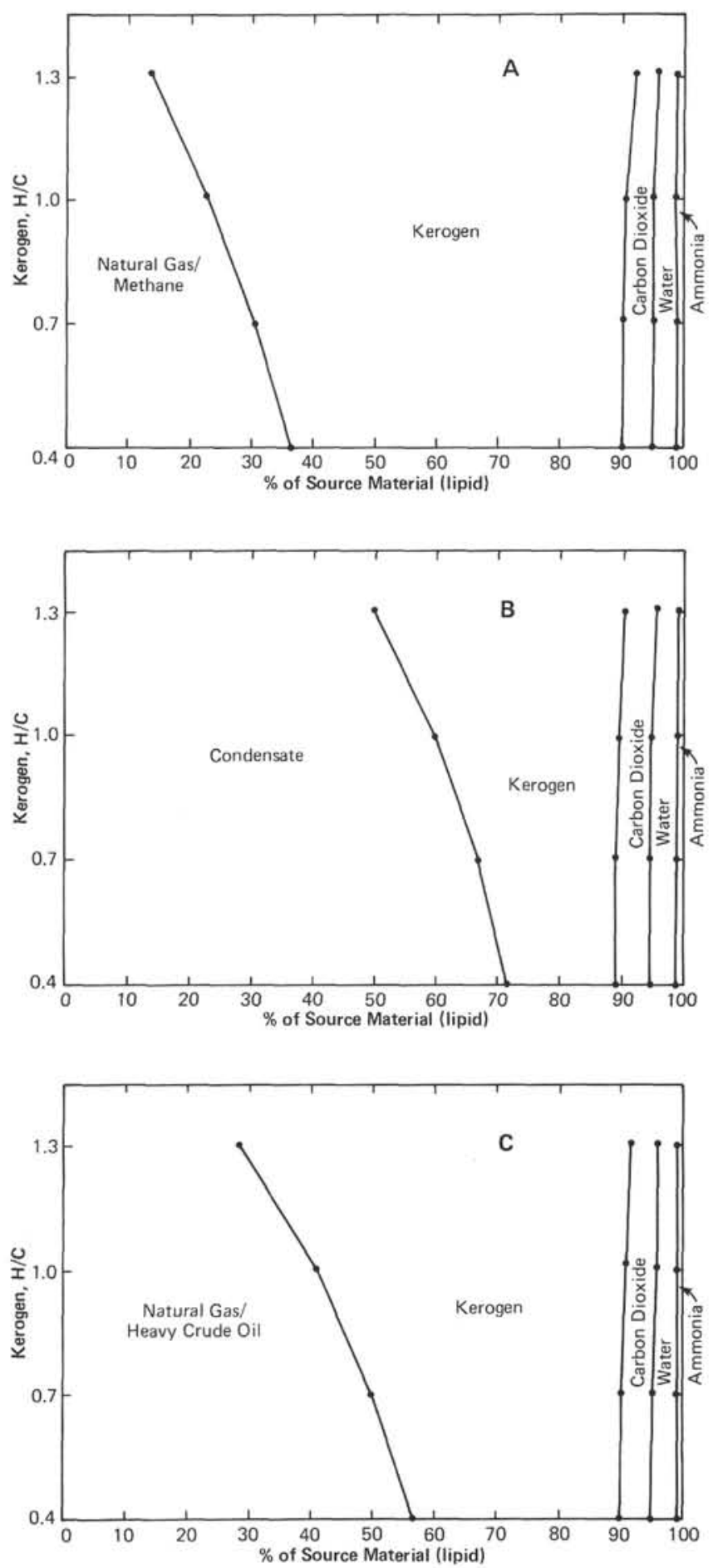

Figure 2. Thermolytic degradation plots of three petroleum types without sulfur: (A) natural gas (methane), (B) condensate, and (C) natural gas-heavy crude oil mixture for Sample 487-2-3, 120-150 $\mathrm{cm}$.

\section{CONCLUSION}

Total organic carbon concentrations are high at the three sites studied, but there was a significant decrease in content with depth at the oceanic plate site. Extracts from two near-surface samples from Holes 487 and 488 
Table 5. Projection of the natural thermolytic degradation of the extract fraction (lipid and elemental sulfur) of Sample 487-2-3, 120$150 \mathrm{~cm}$.

\begin{tabular}{|c|c|c|c|c|c|c|}
\hline $\begin{array}{l}\text { Petroleum } \\
\text { (type) }\end{array}$ & $\begin{array}{l}\text { H-to-C Ratio } \\
\text { (kerogen) }\end{array}$ & Kerogen & $\begin{array}{l}\text { Carbon } \\
\text { Dioxide }\end{array}$ & Water & Ammonia & $\begin{array}{l}\text { Hydrogen } \\
\text { Sulfide }\end{array}$ \\
\hline \multicolumn{7}{|c|}{ Part A. Upon degradation $100^{\%}$ of the sulfur is converted to hydrogen sulfide } \\
\hline \multicolumn{7}{|c|}{ (natural gas-methane) } \\
\hline- & 1.3 & - & - & - & - & - \\
\hline 0.8 & 1.0 & $\$ 1,9$ & 2.6 & 2.1 & 0.5 & 41.9 \\
\hline 6.4 & 0.7 & 45.8 & 2.9 & 2.3 & 0.5 & 41.9 \\
\hline 11.0 & 0.4 & 40.7 & 3.1 & 2.5 & 0.6 & 41.9 \\
\hline \multicolumn{7}{|c|}{$\begin{array}{l}\text { Part B. Upon degradation } 50 \% \text { of the sulfur is converted to } \\
\text { hydrogen sulfide and } 50 \% \text { enters the kerogen }\end{array}$} \\
\hline \multicolumn{7}{|c|}{ (natural gas-methane) } \\
\hline 1.2 & 1.3 & 72.7 & 2.2 & 1.7 & 0.5 & 21.6 \\
\hline 6.6 & 1.0 & 64.5 & 2,7 & 2.2 & 0.5 & 23.4 \\
\hline 11.2 & 0.7 & 58.0 & 3.0 & 2.4 & 0.6 & 24.9 \\
\hline 15.1 & 0.4 & 52.3 & 3.2 & 2.5 & 0.6 & 26.2 \\
\hline
\end{tabular}

contained 39.5 and $86.9 \%$ sulfur, respectively. The sulfur appears to be predominantly elemental and probably results from biogenic reduction of seawater sulfate.

The amount of the organic lipid fractions is small in relation to the total amount of organic matter contained in the sediment samples. Models of the thermolytic degradation of the lipid fractions indicate that the yield of petroleum from the lipid depends on the projected composition of the petroleum. For condensate, yields may reach more than $80 \%$. Presence and interaction of elemental sulfur with the lipid will drastically reduce, and in some cases prevent, formation of petroleum.

\section{ACKNOWLEDGMENTS}

We thank Drs. Earl W. Baker and Philip A. Meyers for reviewing the manuscript and aiding in the clarification of its ideas.

\section{REFERENCES}

Erdman, J. G., 1972. Geochemical formation of oil. Princeton University Conference No. 109, March 10-11. In Fischer, A. G., and Judson, S. (Eds.), Petroleum and Global Tectonics: Princeton (Princeton University Press), pp. 225-248.

, 1975. Relations controlling oil and gas generation in sedimentary basins. Ninth World Petroleum Congress, Proc. (Tokyo), 2:139-148.

Iorns, T. V., and Scott, R. L., 1980. An automated analyzer for the simultaneous determination of carbon, hydrogen, nitrogen and sulfur in coal and other organic and inorganic materials. Pittsburgh Conference on Analytical Chemistry and Applied Spectroscopy (Atlantic City, New Jersey), p. 346. (Abstract)

Larson, R. L., and Chase, C. G., 1970. Relative velocities of the Pacific North American and Cocos plates in the Middle American Region. Earth Planet. Sci. Letters, 7:425-428.
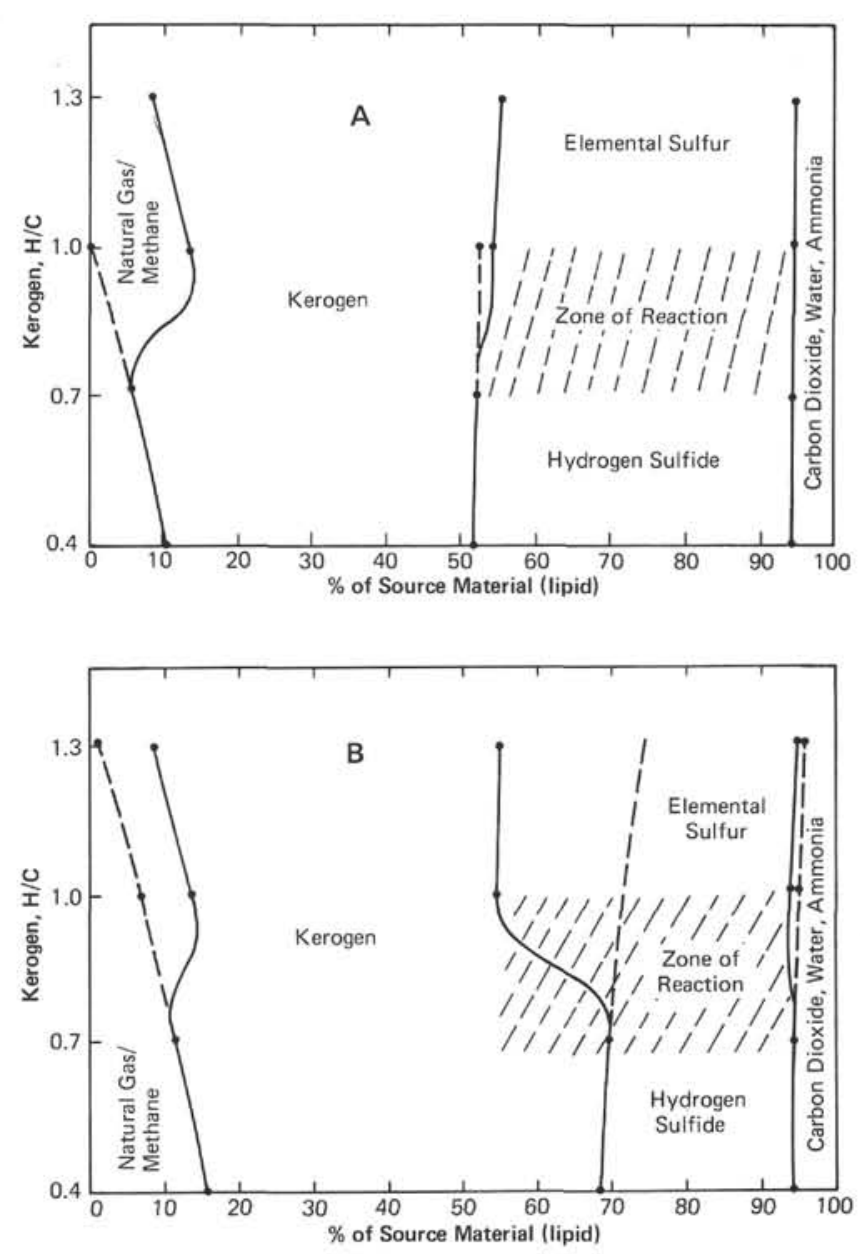

Figure 3. Thermolytic degradation plots of one petroleum type with sulfur: (A) upon degradation $100 \%$ of the sulfur is converted to hydrogen sulfide, and (B) upon degradation $50 \%$ of the sulfur converts to each of hydrogen sulfide and kerogen for Sample $487-2-3,120-150 \mathrm{~cm}$.

Scott, R. L., 1980. Gas Chromatographic Analysis Method and Apparatus. U.S. Patent $4,234,315$.

Seely, D. R., Vail, P. R., and Walton, G. C., 1974. Trench slope model. In Burke, C. A., and Drake, C. L. (Eds.), The Geology of Continental Margins: New York (Springer-Verlag), pp. 249-260.

Shipley, T. H., McMillen, K. J., Watkins, J. S., et al., 1980. Continental margin and lower slope structures of the Middle American Trench near Acapulco, Mexico. Mar. Geol., 35:65-82. 